\title{
Age-Related Differences of Risk Profile and Angiographic Findings in Patients with Coronary Heart Disease
}

\author{
Md. Abu Siddique ${ }^{1}$, Milan Prakash Shrestha', Mohammad Salman ${ }^{3}$, KMHS Sirajul Haque ${ }^{1}$, Md. Khurshed Ahmed ${ }^{4}$, \\ Md. Ashraf Uddin Sultan ${ }^{5}$ Md. Harisul Hoque ${ }^{4}$ S. M. Mustafa Zaman ${ }^{4}$ \\ ${ }^{1}$ Professor, ${ }^{2}$ MD Student, ${ }^{4}$ Assistant Professor, ${ }^{5}$ Research Assistant, Department of Cardiology, University Cardiac, Center, Bangabandhu \\ Sheikh Mujib Medical University, Dhaka, ${ }^{3}$ Assistant Professor, Department of Cardiology, Anwer Khan Modern Medical College, \\ Dhaka.
}

\begin{abstract}
:
Background: Coronary heart disease (CHD) is a major health problem which imposes a significant burden on health care systems because of high morbidity and mortality. Objectives: To compare the risk factors profile for coronary heart disease in young and old subjects. Methods: Total 100 patients (50 subjects less than 40 years of age and 50 subjects more than 40 years of age) with acute coronary syndrome or stable angina who were undergoing coronary angiogram in the Department of Cardiology, University Cardiac Center, Bangabandhu Sheikh Mujib Medical University Dhaka, from July 2006 to June 2008 were evaluated for the presence coronary artery disease risk factors e.g. hypertension, dyslipidemia and smoking. Results: The mean age of the study population in younger group was (33.0 \pm 6.4 ) years and in older group (52.0 \pm 8.6$)$. The male to female ratio in both groups was $4: 1$. Smokers were more in younger group $(70.0 \%$ vs. $46.0 \%)(p=$ 0.032). Hypertension was less in the younger group (38.0\% vs. $58.0 \%)(p=0.045)$. Presence of diabetes was higher in the older age group ( $34.0 \%$ vs. $4.0 \%)(\mathrm{p}=0.001)$. Higher incidence of family history of coronary heart disease was in the younger age group. The total cholesterol was higher in older group $(182.9 \pm 33.1) \mathrm{vs} .(171.1 \pm 24.8 \mathrm{mg} / \mathrm{dl})(\mathrm{p}=0.047) .68 \%$ of patients of older group and $38 \%$ of younger group had stenosis in left anterior descending artery $(\mathrm{p}=0.003)$. The involvement of left circumflex and right coronary artery in older age group were higher (56\% and 66\% respectively) than those in younger group ( $36 \%$ and $40 \%$ respectively) $(p=0.045$ and $p=0.009)$. Conclusion: Ischemic heart disease in younger adults $\leq 40$ years had different risk profile characteristics than older patients.
\end{abstract}

Key words: Coronary heart disease, acute coronary syndrome, stable angina, risk factors.

[BSMMU J 2010; 3(1): 13-17]

\section{Introduction:}

Age-linked epidemiology of disease generally differs in prevalence, incidence and severity at presentation. Coronary Heart Disease (CHD) is a group of closely related syndromes resulting from myocardial ischemia. $\mathrm{CHD}$ is a major cause of morbidity and mortality in the developed as well as in developing countries. When it occurs below 60 years in women and 55 years in men, it is called premature coronary artery disease (CAD). CHD occurring at age below 40 years is termed as CAD in young. ${ }^{1}$ The causes and outcome of coronary artery disease differ by age. ${ }^{2}$ Younger patients $<40$ years of age with an acute coronary

Address for Correspondence: Professor Md. Abu Siddique, Professor of Cardiology, Room No 422, Department of Cardiology, Bangabandhu Sheikh Mujib Medical University, Shahbag, Dhaka, Email:drabusiddique @yahoo.com syndrome have different clinical characteristics and a different prognosis than older patients. ${ }^{3}$ Patients older than 70 have been shown to be at risk for overt coronary artery disease and for exercise- induced silent ischemia based on age alone even when asymptomatic. ${ }^{4}$ Many risk factors have been identified for the development of ischemic heart disease (IHD) in elderly patients. In addition, the prevalence of IHD has been closely associated with socio-demographic, biological, psychological, and behavioral risk factors. ${ }^{4}$ The risk factors and their relative frequency vary in between the young and older age groups, so did the severity of disease and the prognosis. Studies showed that CHD in young had stronger association with smoking, hyperlipidemia and a positive family history compared to diabetes and hypertension in older subjects. Angiographic studies also showed that the extent of disease and severity was also less in younger population with comparatively fewer 
number of coronary arteries affected than that of older age groups .5,6

To date there is only limited information available on the risk factors of ischemic heart disease in different age groups in Bangladesh. In the present study we tried to identify and compare the differences among the traditional risk factors of Ischemic heart disease (IHD) in younger and older IHD patients.

\section{Material and Methods:}

This prospective observational study was conducted in the Department of Cardiology, University Cardiac Center, Bangabandhu Sheikh Mujib Medical University, Dhaka, Bangladesh from July 2006 to June 2008. Total one hundred (100) patients with age between 25 to 75 years with the diagnosis of Coronary Heart disease who were undergoing Coronary angiogram for stable angina, myocardial infarction or unstable angina (2-3 weeks after last episode) were included in this study. Coronary heart disease is defined as chest discomfort in the prior 48 hours in patients with positive troponin (troponin I e” $1.0 \mathrm{ng} / \mathrm{ml}$ ) and/or electrocardiographic changes consisting of transient STsegment depression (e"0.05 mV) or T wave inversion (e"0.1 $\mathrm{mV}$ ). Positive troponin patients had their index event defined as acute myocardial infarction and the remaining subjects were labeled as unstable angina. Acute STEMI was defined as chest pain lasting for e" $30 \mathrm{~min}$, characteristic ST-segment elevation of e" $0.1 \mathrm{mV}$ in two or more contiguous leads on ECG, and a creatine kinase MB (CK-MB) values more than twice that of the highest reference laboratory value. ${ }^{7}$

Patients with previous left bundle-branch block, pacemaker rhythm, acute inflammatory illness (within the last month), history of malignancy or secondary conditions that could precipitate angina (anemia, arrhythmias, fever), patients with cardiac valve disease, acute or chronic liver disease, and infectious diseases, renal impairment, unwilling to undergo procedure, prior coronary revascularization and with ejection fraction $<30 \%$ were excluded from the study. After taking brief history, assessment of risk factors, they were requested to fast overnight (at least 8 hours) after dinner. The next morning fasting blood sample collected then patients were taken to catheterization laboratories for coronary angiogram. Coronary angiogram was done by percutaneous femoral arterial catheterization. Coronary artery disease defined as significant when there is $>50 \%$ stenosis in the Left main artery and $>70 \%$ stenosis in luminal diameter of left anterior descending, left circumflex and right coronary arteries
Statistical Analysis

Statistical analysis was conducted using SPSS 12 for windows software. Categorical data were expressed as frequencies and corresponding percentages. Parametric data were expressed in mean \pm SD. Parametric data were evaluated by independent sample "t" test and categorical data were evaluated by Chi-square test as needed or Fisher's Exact Test. Level of significance (p value) d"0.05 is considered significant.

\section{Results:}

Total of $100(50+50)$ patients with clinically diagnosed Coronary Heart Disease (CHD) \& undergoing coronary angiographic evaluation were selected. Patients were divided in two groups;

i) Young patients ( $<40$ years of age)

ii) Old patients ( $\geq 40$ years of age)

All patients are further divided into two groups according to the clinical presentations;

i) Patients with history of ACS.

ii) Patients with Stable Angina.

The mean age of the study population in younger group was (33.0 \pm 6.4 ) years and in older group (52.0 \pm 8.6$) .82 \%$ in younger group and $84 \%$ in older group were male. The male to female ratio in the both groups was roughly of 4:1. The proportion of overweight and obese subjects did not differ between the groups (30\% in each group). $70 \%$ of the patients in younger group were smokers compared to $46 \%$ in older group $(p=0.032)$. Hypertension was significantly less in the younger group (38\%) than that in the older age group (58\%) $(\mathrm{p}=0.045)$. Presence of diabetes was higher in the older age group (34\%) than that in the younger age group $(4 \%)(p=0.001)$. Higher incidence of family history of IHD was observed in the younger age group than that in the older age group $(p=0.023)$. The mean total cholesterol was seen to be significantly higher in older group (182.9 \pm 33.1$)$ compared to younger patients $(171.1 \pm 24.8 \mathrm{mg} / \mathrm{dl})(\mathrm{p}=0.047)$. HDL, LDL and triglycerides values did not show any statistically significant difference in between two groups (Table I).

It is found that most (86\%) of the patients in the younger group and $78 \%$ in the older group had stable angina, while $14 \%$ of the patents in the younger group and $22 \%$ in the older group had acute coronary syndrome (ACS), (Figure 1).

Figure 2 shows the ECG findings of the patients. ECG findings at the time of presentation were almost similar in both the groups, except that the pathological Q-wave was much higher in the older age group (32\%) than that in the younger age group (18\%). 
Table-I

Baseline Characteristics and risk factors of IHD in the patients $(N=100)$.

\begin{tabular}{lccc}
\hline Variables & $\begin{array}{c}\text { Group 1(n=50) } \\
\text { (younger patients) }\end{array}$ & $\begin{array}{c}\text { Group 2 (n=50) } \\
\text { (older patients) }\end{array}$ & $\begin{array}{c}\text { p- } \\
\text { value }\end{array}$ \\
\hline Age (in years) & $33.0 \pm 6.4$ & $52.0 \pm 8.6$ & 0.023 \\
Male:Female & $4: 1$ & $4: 1$ & \\
Over weight \& obese & $15.0(30.0 \%)$ & $15.0(30.0 \%)$ & 0.995 \\
Smoker & $35.0(70.0 \%)$ & $23.0(46.0 \%)$ & 0.032 \\
Hypertension & $19.0(38.0 \%)$ & $36.0(72.0 \%)$ & 0.001 \\
Diabetes & $2.0(4.0 \%)$ & $17.0(34.0 \%)$ & 0.001 \\
Family history of IHD & $18(36.0 \%)$ & $8(16.0 \%)$ & 0.023 \\
Total cholesterol (mg/dl) & $171.1 \pm 24.8$ & $182.9 \pm 33.1$ & 0.047 \\
LDL (mg/dl) & $115.4 \pm 93.2$ & $109.4 \pm 32.3$ & 0.670 \\
HDL (mg/dl) & & & \\
\multicolumn{1}{c}{ Male } & $40.7 \pm 7.5$ & $42.2 \pm 5.9$ & 0.337 \\
$\quad$ Female & $43.7 \pm 9.8$ & $45.6 \pm 6.8$ & 0.626 \\
Triglyceride (mg/dl) & $138.4 \pm 9.1$ & $153.3 \pm 29.1$ & 0.061 \\
\hline
\end{tabular}

Data were expressed in number, percent and mean \pm standard deviation. p value d” 0.05 is significant. IHD=ischemic heart disease, LDL=low density lipoprotein, HDL=high density lipoprotein.

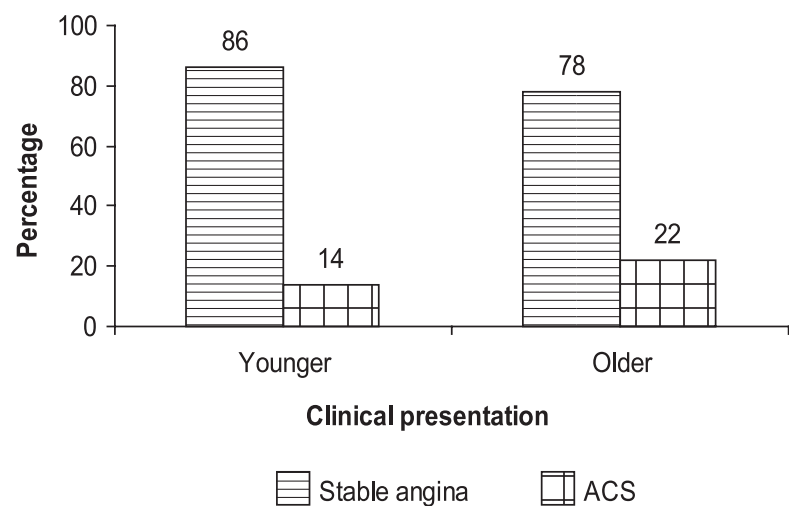

Fig.-1: Clinical presentation of patients in both groups $(N=100)$

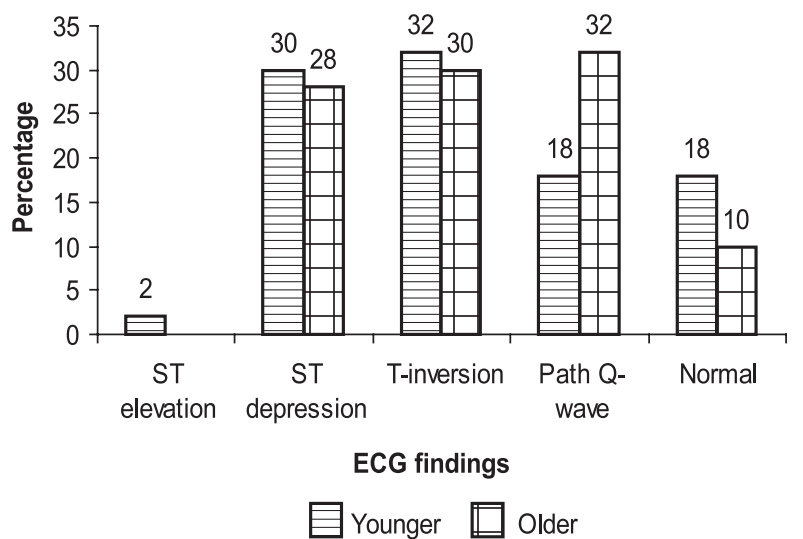

Fig.-2. ECG findings of the patients in both groups $(N=100)$

Table-II

Comparison of the coronary arteries involvement between the groups $(N=100)$

\begin{tabular}{lccc}
\hline Arteries involved & $\begin{array}{c}\text { Group 1 }(\mathrm{n}=50) \\
\text { (younger patients) }\end{array}$ & $\begin{array}{c}\text { Group 2 }(\mathrm{n}=50) \\
\text { (older patients) }\end{array}$ & $\begin{array}{c}\text { p- } \\
\text { value }\end{array}$ \\
\hline Left main & $3.0(6.0 \%)$ & $6.0(12.0 \%)$ & 0.487 \\
LAD & $19.0(38.0 \%)$ & $34.0(68.0 \%)$ & 0.003 \\
LCX & $18.0(36.0 \%)$ & $28.0(56.0 \%)$ & 0.045 \\
RCA & $20.0(40.0 \%)$ & $33.0(66.0 \%)$ & 0.009 \\
\hline
\end{tabular}

Data were expressed in number and percent. $p$ value $\leq 0.05$ is significant. LAD=left anterior descending artery, $\mathrm{LCX}=\mathrm{left}$ circumflex artery, RCA=right coronary artery. 
It was found that the involvement of left main artery was double in older group (12\%) than that of younger group (6\%). Over two-third (68\%) of patients of older group and $38 \%$ of younger group had stenosis in left anterior descending artery (LAD) $(\mathrm{p}=0.003)$. The involvement of left circumflex (LCX) and right coronary artery (RCA) in older age group were significantly higher (56\% and 66\% respectively) than those in younger group (36\% and $40 \%$ respectively) ( $\mathrm{p}=0.045$ and $\mathrm{p}=0.009$ respectively) (Table II).

It is found that triple vessel disease (TVD) was more in the older age group patients (46\%) while Single vessel disease (SVD) (42\%) \& normal coronary arteries (18\%) were found more common in the younger age group patients (Figure 3).

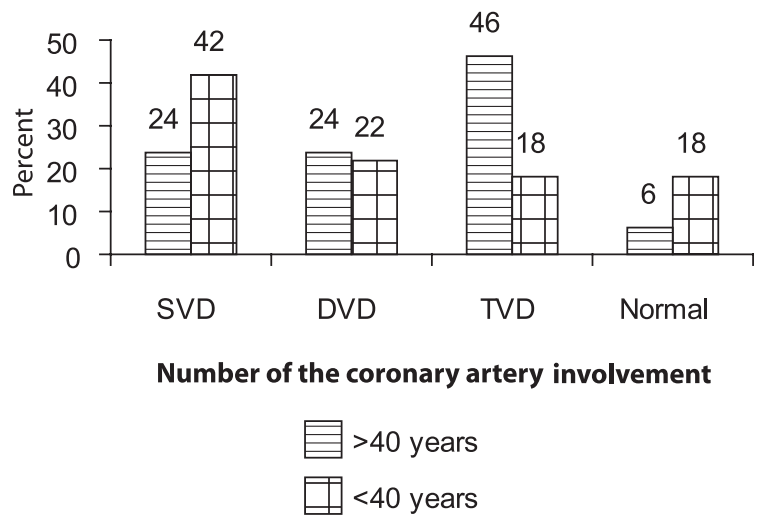

Fig.-3: Frequency distribution of the subjects by number of the coronary artery involvement in both groups $(N=100)$.

\section{Discussion:}

This study showed smoking and family history of ischemic heart disease as the major risk factors in young while hypertension and diabetes in older IHD patients. Dyslipidemia was found in both groups.

This study showed the prevalence of smoking among 70\% young patients compared to $46 \%$ in older patients. Reported prevalence of smoking in young versus old patients with CHD were $70 \%$ vs. $22 \%$ by Nesligul et $\mathrm{al}^{6}$, $73 \%$ vs $46 \%$ by Chen et al. ${ }^{8}$ Another study done by Warren et al ${ }^{8}$ found $73 \%$ of young patients surviving myocardial infarction were smoker. These results from abroad and the one in this study shows that smoking is the single most important modifiable risk factor for IHD overall and more so among young people.

This study showed that the family history of premature CHD was positive in $36 \%$ of young CHD patients compared to $16 \%$ in older group. Chen et $\mathrm{al}^{8}$ found it positive in $39 \%$ of young patients compared to $11 \%$ of older group. Nesligul et $\mathrm{al}^{6}$ found $58 \%$ of young patient to be associated with positive family history with $43 \%$ in older group which is close to the result of this study.

Dyslipidemia in terms of hypercholesterolemia, hypertriglyceridemia, low HDL and high LDL were found in both groups of CHD patients in this study. While statistically not significant, numerically younger patients were found to have lower HDL levels (44\% in male and $67 \%$ in female). This result is supported by study done by Nesligul et al. ${ }^{6}$ Wolfe et al $^{10}$ found dyslipidemia was present in 23\% young patients with CHD compared to $17 \%$ in older CHD group.

Hypertension was more prevalent in older CHD patients (72\%) when compared to younger CHD patients (38\%) and the ratio was nearly 2:1. It is much higher than the study done by Nesligul et $\mathrm{al}^{6}$ in which the prevalence was found to be $47 \%$ and $22 \%$ in older and younger CHD patients respectively. This difference was not significant in the study done by $\mathrm{Chen}^{8}$ (38\% vs. 25\%). Similarly its prevalence was found to be $48 \%$ in older CHD patients compared to $28 \%$ in younger CHD group in the study done by Wolfe et al. ${ }^{10}$ Among the modifiable risk factors hypertension is one of the very important factor that can controlled adequately by diet, modification of life style and drugs.

In this study 34\% of older CHD patients compared to 4\% of younger patients were diabetics. Nesligul et $\mathrm{al}^{6}$ in his study found the prevalence of diabetes to be $23 \%$ versus $7.5 \%$ in older and younger CHD group respectively. Another study carried out by Wolfe et al ${ }^{10}$ also revealed the prevalence to be $26 \%$ and $3 \%$ in older and younger CHD patients respectively. Thus it implies that diabetes is less likely to have role in pathogenesis of CHD in young patients.

In this study, it is found that 38\% young patients had normal coronary arteries and $4 \%$ had non critical coronary lesions. On the contrary, normal coronaries were found in only $4 \%$ and non-critical coronary lesions in $2 \%$ of older CHD group and rest $94 \%$ had significant coronary artery disease. Nesligul ${ }^{6}$ and Wolfe et $\mathrm{al}^{10}$, reported prevalence of significant coronary artery lesion to be $3.3 \%$ and $14.3 \%$ respectively among young patients with CHD. Other studies are also showed similar results. ${ }^{11-15}$

In this study single-vessel disease was found in $42 \%$ of young patients with CHD. Double vessel and triple vessel diseases (24\% \& 46\% respectively) remained more common 
in older CHD group. This result is consistent with other studies done by Nesligul et $\mathrm{al}^{6}$ \& Wolfe et al. ${ }^{10}$

In conclusion, this study provides important information on age-related trends in the epidemiologic characteristics of coronary heart disease. Patients with premature CAD commonly have different risk profile, less extensive CAD than the older ones. Dominance of smoking and dyslipidemia that are the preventable risk factors in premature CAD patients is an important threat for young adult. Healthy life styles should be encouraged beginning from young ages and new precautions about smoking must be taken

\section{References:}

1. Sachar R, Risk Factors for coronary artery disease in young South Asians; a cross-sectional study of Indians living in India and Second-generation Indian immigrants to the United states of America. $2^{\text {nd }}$ Year Research Elective Resident's Journal, 1997-98;2:138-44

2. Yan RT, Yan AT, Tan M, Chow CM, Fitchett DH, Ervin FL, Cha JY, Langer A, Goodman SG. Age-related differences in the management and outcome of patients with acute coronary syndromes. Am Heart J, 2006;151:352-59.

3. Shiraishi J, Kohno Y, Yamaguchi S, Arihara M, Hadase M, Hyogo M, Yagi T, Shima T, Sawada T, Tatsumi T, Azuma A, Matsubara H. Medium-term prognosis of young Japanese adults having acute myocardial infarction. Circ 2006;70:518-24.

4. Katzel LI, Sorkin KD, Colman E, Goldberg AP, BusbyWhitehead MJ, Lakatta LE, Becker LC, Lakatta EG, Fleg JL. Risk factors for exercise-induced silent myocardial ischemia in healthy volunteers. Am J Cardiol,1994;74:869-74.

5. Avendano M, Kunst AE, Huisman M, Lenthe FV, Bopp M, Regidor E, Glickman M, Costa G, Spadea T, Deboosere P, Borrell C, Valkonen T, Gisser R, Borgan JK, Gadeyne S, Mackenbach JP. Socioeconomic status and ischaemic heart disease mortality in 10 western European populations during the 1990s, Heart, 2006;92:461-67.
6. Nesligul Yildirim, Nurcan Arat, Mesut Sait Dogan, Yeliz Sokmen, Firat Ozcan Comparison of traditional risk factors, natural history and angiographic findings between coronary heart disease patients with age $<40$ and e" 40 years old. Anadolu Kardiyol Derg, 2007;7:124-27.

7. Morrow DA, Antman EM, Charlesworth A, et al. TIMI risk score for ST-elevation myocardial infarction: a convenient, bedside, clinical score for risk assessment at presentation: an intravenous nPA for treatment of infarcting myocardium early II trial sub study. Circulation. 2000;102:2031-37.

8. Chen L, Chester M, Kaski JC. Clinical factors and angiographic features associated with premature coronary artery disease. Chest, 1995;108:364-69.

9. Warren E, Thompson I, Viewag VR. Historic and angiographic features of young adults surviving myocardial infarction. Chest, 1979;75:667-70

10. Wolfe MW, Vacek JL. Myocardial infarction in the young: angiographic features and risk factor analysis of patients with myocardial infarction at or before the age of 35 years. Chest, 1988;94:926-30.

11. Cole JH, Miller JI, Sperling LS, Weintraub WS. Long-term follow-up of coronary artery disease presenting in young adults. J Am Coll Cardiol, 2003; 41:521-28.

12. Barbash GI, White HD, Modan M, et al. Acute myocardial infarction in the young - the role of smoking. The Investigators of the International Tissue Plasminogen Activator/ Streptokinase Mortality Trial. Eur Heart J, 1995; 16:31316.

13. Zimmerman FH, Cameron A, Fisher LD, et al. Myocardial infarction in young adults: angiographic characterization, risk factors and prognosis. Coronary Artery Surgery Study Registry. J Am Coll Cardiol, 1995; 26:654-61.

14. Weinberger I, Rotenberg Z, Fuchs J, Sagy A, Friedmann J, Agmon J. Myocardial infarction in young adults under 30 years: risk factors and clinical course. Clin Cardiol. 1987;10:915.

15. Uhl GS, Farrell PW. Myocardial infarction in young adults: risk factors and natural history. Am Heart J. 1983;105:54853. 